\title{
The role of front and back electrodes in parasitic absorption in thin-film solar cells
}

Mathieu Boccard ${ }^{\mathrm{a}}$, Peter Cuony, Simon Hänni, Michael Stuckelberger, Franz-Josef Haug, Fanny Meillaud, Matthieu Despeisse, and Christophe Ballif

École Polytechnique Fédérale de Lausanne (EPFL), Institute of Microengineering (IMT), Photovoltaics and Thin Film Electronics Laboratory, Rue de la Maladière 71b, CP 526, 2002 Neuchâtel 2, Switzerland

Received: 9 March 2014 / Received in final form: 17 April 2014 / Accepted: 17 April 2014

Published online: 16 July 2014

(c) Boccard et al., published by EDP Sciences, 2014

\begin{abstract}
When it comes to parasitic absorption in thin-film silicon solar cells, most studies focus on one electrode only, most of the time the substrate (in $n-i-p$ configuration) or superstrate (in $p-i-n$ configuration). We investigate here simultaneously the influence of the absorption in both front and back electrodes on the current density of tandem micromorph solar cells in $p-i-n$ configuration. We compare four possible combinations of front and back electrodes with two different doping levels, but identical sheet resistance and identical light-scattering properties. In the infrared part of the spectrum, parasitic absorption in the front or back electrode is shown to have a similar effect on the current generation in the cell, which is confirmed by modeling. By combining highly transparent front and back $\mathrm{ZnO}$ electrodes and high-quality silicon layers, a micromorph device with a stabilized efficiency of $11.75 \%$ is obtained.
\end{abstract}

\section{Introduction}

Minimizing the absorption of non-photoactive layers is of crucial importance for most solar cell technologies. When a direct-band-gap photoactive material (such as gallium-arsenide) is used, parasitic absorption impinges on the photon recycling process and reduces the achievable voltage output [1]; whereas when indirect-band-gap photoactive material (such as silicon) is used, this parasitic absorption impinges on the current density output [2-5]. In the case of thin-film silicon technology, parasitic absorption due to non-active layer has been identified as a major limitation for present devices $[6,7]$.

We focus in the following on micromorph tandem cells, which consist of a hydrogenated amorphous silicon $(a-\mathrm{Si}: \mathrm{H})$ top cell and a hydrogenated microcrystalline silicon $(\mu c-\mathrm{Si}: \mathrm{H})$ bottom cell. For this device, light trapping strategies are applied for a broad wavelength range of the solar spectrum, covering the near infrared (NIR) range between $600 \mathrm{~nm}$ and $1100 \mathrm{~nm}$. The absorption coefficient of $\mu c-\mathrm{Si}: \mathrm{H}$ silicon being weak in the NIR, efficient light trapping (typically via nanotextured interfaces) is mandatory to achieve large currents [7-14]. Yet, in the presence of a very efficient light-trapping scheme, parasitic absorption $\left(A_{P}\right)$ due to the non-photoactive layers (such as the doped layers, the electrodes and the back

\footnotetext{
${ }^{a}$ e-mail: mathieu.boccard@epfl.ch
}

reflector) is also increased compared to a flat cell configuration [6, 15-17]. For transparent conductive oxide (TCO) based front electrodes, decreasing the free-carrier density enables to greatly increase the transparency in the NIR [17-19].

In this work, we separate the influence of parasitic absorption in the front and back electrodes by using $\mathrm{ZnO}$ in both cases. Two different doping levels are compared for both electrodes, leading to four possible combinations of front and back electrodes. The sheet resistance is kept identical in all cases, and the light-scattering properties of all front electrodes are identical as well. Both electrodes are shown to have similar influence in the NIR spectrum range, which is confirmed by simulations.

\section{Experimental details}

The devices studied here are micromorph cells deposited by plasma enhanced chemical vapor deposition (PECVD). An in-situ 70-nm-thick silicon-oxide based intermediate reflecting layer (SiO-based IRL) [20,21] is inserted between the 240-nm-thick $a$-Si:H top cell and the 2.8- $\mu$ m-thick $\mu c$-Si:H bottom cell. Front and back electrodes are made of $\mathrm{ZnO}$ deposited by low pressure chemical vapor deposition (LPCVD).

Figure 1 schematically presents the four micromorph devices compared here. Their front and back electrodes 


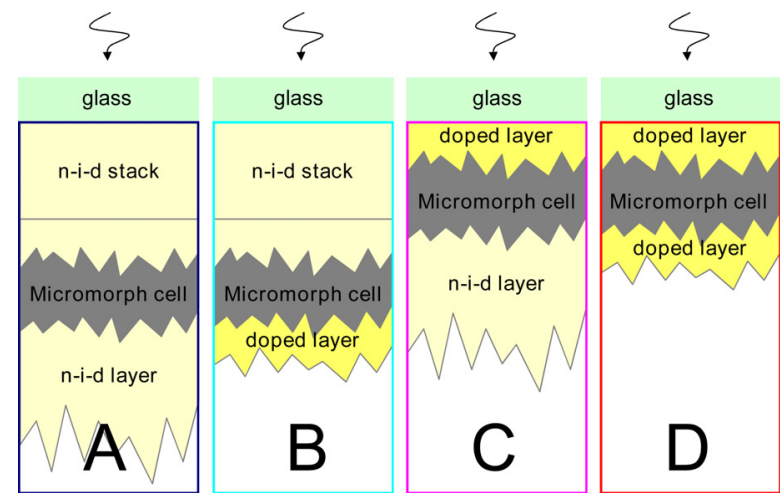

Fig. 1. Schematic view of the stacks composing the A, B, C and D micromorph devices. Only the front and back electrodes are changed. Light enters the devices from the top.

are the only changing parameters and two options are used: thick, non-intentionally-doped $(n-i-d)$ LPCVD ZnO or thin, doped LPCVD ZnO. The free-carrier density in the $n-i-d \mathrm{ZnO}$ is around $1.2 \times 10^{19} \mathrm{~cm}^{-3}$ and it is $1.0 \times$ $10^{20} \mathrm{~cm}^{-3}$ in the doped one. The sheet resistance is kept similar for all electrodes (between $7 \Omega / \square$ and $12 \Omega / \square$ ) thanks to the much larger thickness in the $n$ - $i$ - $d$ case. In order to keep the same morphology for both types of front electrodes, a stack of two layers is used in the $n$ - $i$ - $d$ case. A $7-\mu \mathrm{m}$-thick layer is first deposited on glass and flattened by chemo-mechanical polishing (CMP) to erase the very large pyramidal features that naturally form on its surface during layer growth [22]. This polishing is made by immersing the sample in a diluted suspension of silica nanoparticles as typically used for CMP, and scanning the surface with a felt-covered drill-head. To inhibit epitaxial growth on this polished surface, an ultra-thin $(<3 \mathrm{~nm})$ $n$-doped $\mu c$-Si:H layer is subsequently deposited; a $n$ - $i$ - $d$ $\mathrm{ZnO}$ film is then deposited on top, with thickness adjusted to match the surface morphology of the $2-\mu \mathrm{m}$-thick doped layer. Due to a reduction of the lateral growth rate of the grains when LPCVD $\mathrm{ZnO}$ is doped [22], this rough $n-i-d$ layer is only $1.6-\mu \mathrm{m}$-thick.

For the back electrode, both electrodes are singlelayers, $7-\mu \mathrm{m}$-thick for the $n$ - $i$ - $d$ case and $2-\mu \mathrm{m}$-thick for the doped one. Though these back electrodes exhibit therefore different surface roughnesses, this was shown to have no noticeable impact on the light-trapping behavior of such devices, due to the efficient light scattering provided by the front electrode [23].

\section{Results and discussion}

Figure 2a compares absorptance measurements of the 8- $\mu$ m-thick $n$ - $i$ - $d \mathrm{ZnO}$ stack and the 2- $\mu$ m-thick doped $\mathrm{ZnO}$ layer. For wavelengths up to $550 \mathrm{~nm}$ the doped layer absorbs less than the $n-i-d$ stack. This is due first to the Burstein-Moss effect, widening the band-gap in the case of the doped $\mathrm{ZnO}$ [24], but also to enhanced sub-gap absorption in the $n-i-d$ stack because of the larger thickness. However, above $550 \mathrm{~nm}$, the higher free-carrier absorption

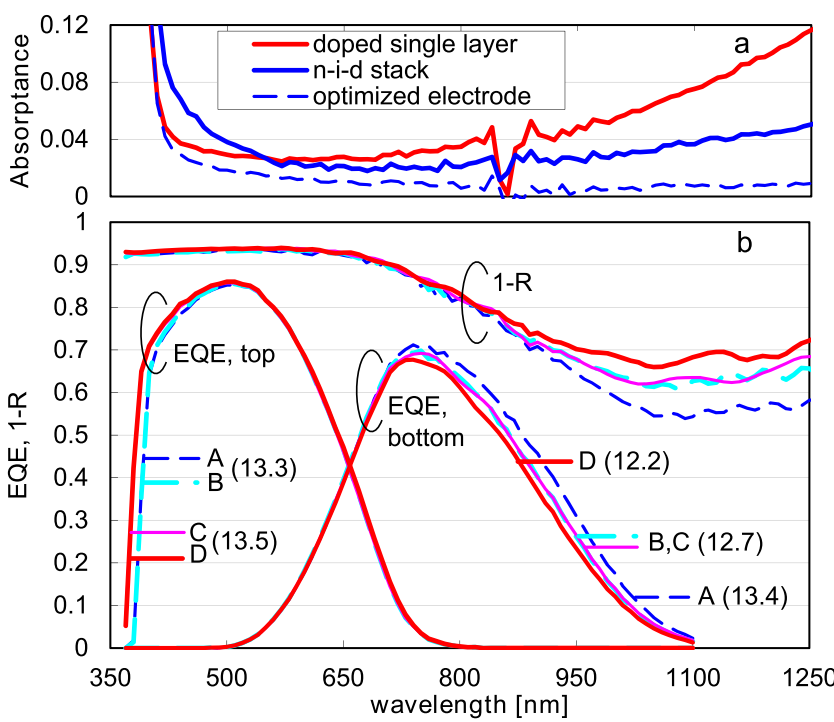

Fig. 2. (a) Absorptance of $\mathrm{ZnO}$ front electrodes used in this study as sketched in Figure 1, and of the optimized electrode used in the device of Figure 4. These measurements were made in air with an index-matching liquid $\left(\mathrm{CH}_{2} \mathrm{I}_{2}\right)$. (b) EQE and 1-Reflection $(1-R)$ of the four micromorph devices sketched in Figure 1 having only their $\mathrm{ZnO}$ electrodes changed. The number in parenthesis are current density values for the top and bottom cells, in $\mathrm{mA} / \mathrm{cm}^{2}$.

(FCA) in the doped single layer makes the $n$ - $i$ - $d$ stack more transparent despite its larger thickness.

Figure $2 \mathrm{~b}$ shows the external quantum efficiency (EQE) spectrum of top and bottom cells for the four possible micromorph configurations employing these electrodes in front and back. The similarity of the morphology of all front electrodes is assessed by the perfect matching of the crossing of the top and bottom EQE curves for all substrates at the same wavelength $(650 \mathrm{~nm})$ [25]. The top cell current is only affected for such a thick cell by the front electrode (A, B and C, D are superimposed), and the higher optical band gap of the thin doped TCO layer enables a $0.2 \mathrm{~mA} \mathrm{~cm}^{-2}$ current gain. Then, the bottom cell is sensitive to the transparency of both electrodes, and in a very similar way, as deduced from the striking superimposition of the $\mathrm{B}$ and $\mathrm{C}$ curves and the identical current densities. This can also be seen in Figure 3a, which indicates the relative parasitic absorption for all cases compared to case A, evidencing the identical effect of FCA in the back or front electrode.

However, the current gained in the bottom cell by improving the transparency of the back electrode (i.e. going from $\mathrm{B}$ to $\mathrm{A}$ or from $\mathrm{D}$ to $\mathrm{C}$ ) depends on the front electrode properties: $0.7 \mathrm{~mA} \mathrm{~cm}^{-2}$ are gained between $\mathrm{B}$ and $\mathrm{A}$, whereas only $0.5 \mathrm{~mA} \mathrm{~cm}^{-2}$ is gained between $\mathrm{D}$ and C. This is illustrated with curves of relative spectral current density gain in Figure 3b. The same applies when improving the transparency of the front electrode: $0.7 \mathrm{~mA} \mathrm{~cm}^{-2}$ are gained in the bottom cell for $\mathrm{C}$ to $\mathrm{A}$, but only $0.5 \mathrm{~mA} \mathrm{~cm}^{-2}$ for $\mathrm{D}$ to $\mathrm{B}$. The current gain when making one electrode more transparent therefore scales with 

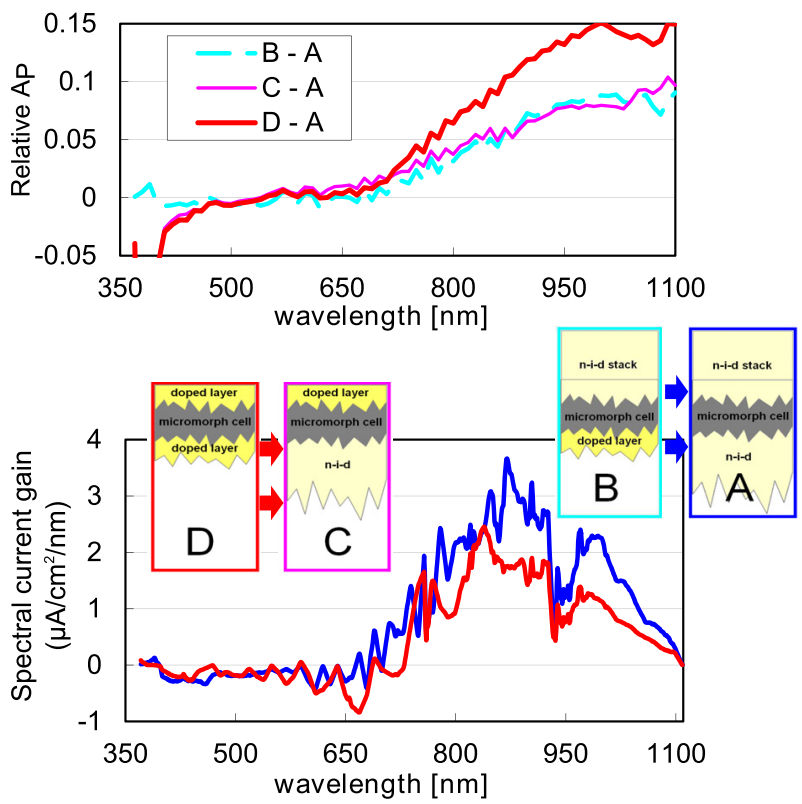

Fig. 3. (a) Relative parasitic absorption in the four micromorph devices sketched in Figure 1 compared to case A where both electrodes are non-intentionally-doped doped, and thus very transparent. (b) Spectral current density gain between configurations B and A, or D and C. In both cases, the same modification is made at the back electrode.

the transparency of the other electrode, a more transparent unchanged electrode leading to a larger gain.

This difference comes from the fact that the light saved from parasitic absorption in one of the electrodes (by making it more transparent) will be distributed between valuable absorption (EQE), escape from the cell $(R)$ and parasitic absorption in the remaining parasitically absorbing layers $\left(A_{P}\right)$. The probability of the latter increases with the parasitic absorption of the unchanged electrode, as will be seen with modeling in the next section. This indicates that the largest gains from parasitic absorption reduction are expected when improving already well transparent electrodes. However, as evidenced by Battaglia et al. [2], doped layers also contribute to parasitic absorption. Their contribution to parasitic absorption might therefore at some point become larger than the contribution of the electrode, making further improving the electrode transparency of little effect.

By combining high-quality silicon layers and highly transparent electrodes, a micromorph cell with $11.75 \%$ efficiency is obtained, as shown in Figure 4. The front and back electrodes are 2.3- $\mu$ m-thick LPCVD ZnO layers with a low doping (carrier density of $2 \times 10^{19}$ ) and a high mobility (over $50 \mathrm{~cm}^{2} / \mathrm{V} / \mathrm{s}$ ), resulting in a sheet resistance below $30 \Omega / \square$ for a high transparency as seen in Figure 2a [25]. The thickness of the intrinsic layer of the $a-\mathrm{Si}: \mathrm{H}$ top cell is $230 \mathrm{~nm}$, and the thickness of the intrinsic layer of the $\mu c$-Si:H bottom cell is $2.3 \mu \mathrm{m}$. An 80-nm-thick SiO-based IRL with a refractive index of 1.9 is used between the top and bottom cells, an intrinsic $\mathrm{SiO}$ buffer layer was used in the $a$-Si:H cell and a $p$-type $\mathrm{SiO}$ layer was used in the $\mu c$-Si:H cell $[20,26]$. The $a$-Si:H cell

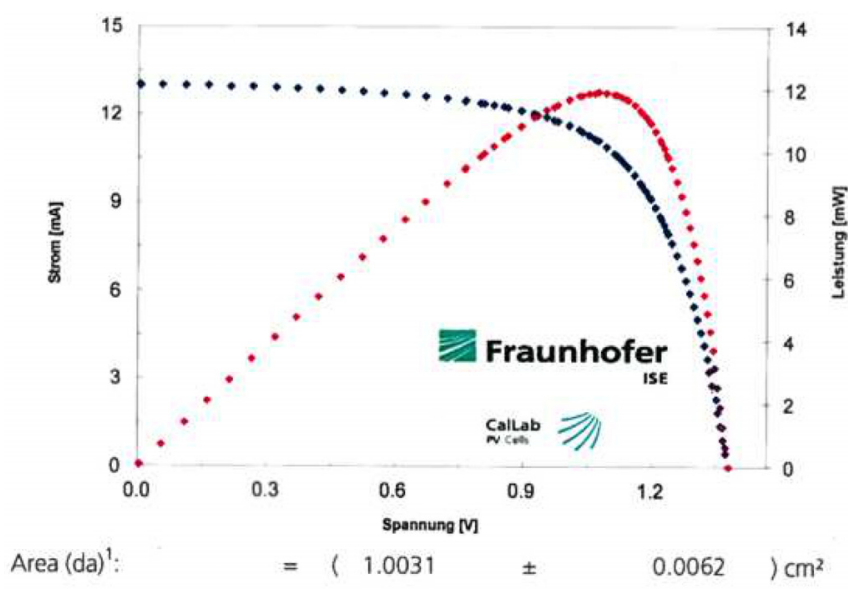

IV-curve parameter under standard testing conditions (STC):

\begin{tabular}{|c|c|c|c|c|c|}
\hline$V_{O C}$ & $=$ & 1.3500 & \pm & 0.0068 & IV \\
\hline$I_{s c}(E d .2-2008) / 7 /$ & $=$ & 12.88 & \pm & 0.32 & ) $\mathrm{mA}$ \\
\hline$J_{s c}$ & $=$ & 12.84 & \pm & 0.33 & ) $\mathrm{mAV} / \mathrm{cm}^{2}$ \\
\hline$I_{\text {MPP }}$ & $=$ & 11.22 & & & $\mathrm{~mA}$ \\
\hline$V_{\text {MPP }}$ & $=$ & 1.0510 & & & V \\
\hline$P_{\text {MPP }}$ & $=$ & 11.92 & \pm & 0.52 & ) $\mathrm{mW}$ \\
\hline $\mathrm{FF}$ & $=$ & 67.80 & \pm & 0.68 & $\%$ \\
\hline$\eta$ & $=$ & 11.75 & \pm & 0.52 & $\%$ \\
\hline
\end{tabular}

Fig. 4. IV curve of a micromorph cell with an efficiency of $11.75 \%$, deposited using highly transparent $\mathrm{ZnO}$ electrodes.

and the SiO-based IRL were made in an Octopus I cluster tool made by INDEOtec SA, whereas the $\mu c-\mathrm{Si}: \mathrm{H}$ cell was made in a research-scale reactor developed in-house [27].

\section{Modeling}

Figure 5 shows various spectra obtained when simulating this set of experimental data with the model presented in reference [7]. Only a $\mu c$-Si:H cell is used for the model, and the resulting simulated EQE curve is compared to the curve obtained by summing the top- and bottom-cell EQE curves. In absence of a correct AFM scan of the front-electrode surface, the light-trapping parameters of the model $\left(a_{0}, b_{1}\right.$ and $\left.R_{0}\right)$ are fitted once for all four cases in absence of parasitic absorption using a "corrected EQE" $\left(\mathrm{EQE}_{\mathrm{c}}\right)$ curve, calculated from experimental EQE and R curves of one of the devices [16]. Then, the measured absorptance spectra of the two different types of layers are implemented in $A_{\text {front }}$ and $A_{b a c k}$, and the $p$-layer thickness is kept identical for all curves.

An excellent agreement between experimental and simulated EQE and $R$ curves is obtained in the infrared part of the spectrum. A notable discrepancy of the simulation compared to the measurement is observed, similarly for all devices, in the $600 \mathrm{~nm}-900 \mathrm{~nm}$ wavelength range. This is attributed to the many additional layers present in the real micromorph device compared to the simplified model considering only a $\mu c$-Si:H cell, such as the intermediate reflector and $a$-Si:H doped layers. These layers induce extra parasitic absorption and reflection, that is not taken into account in the model. 

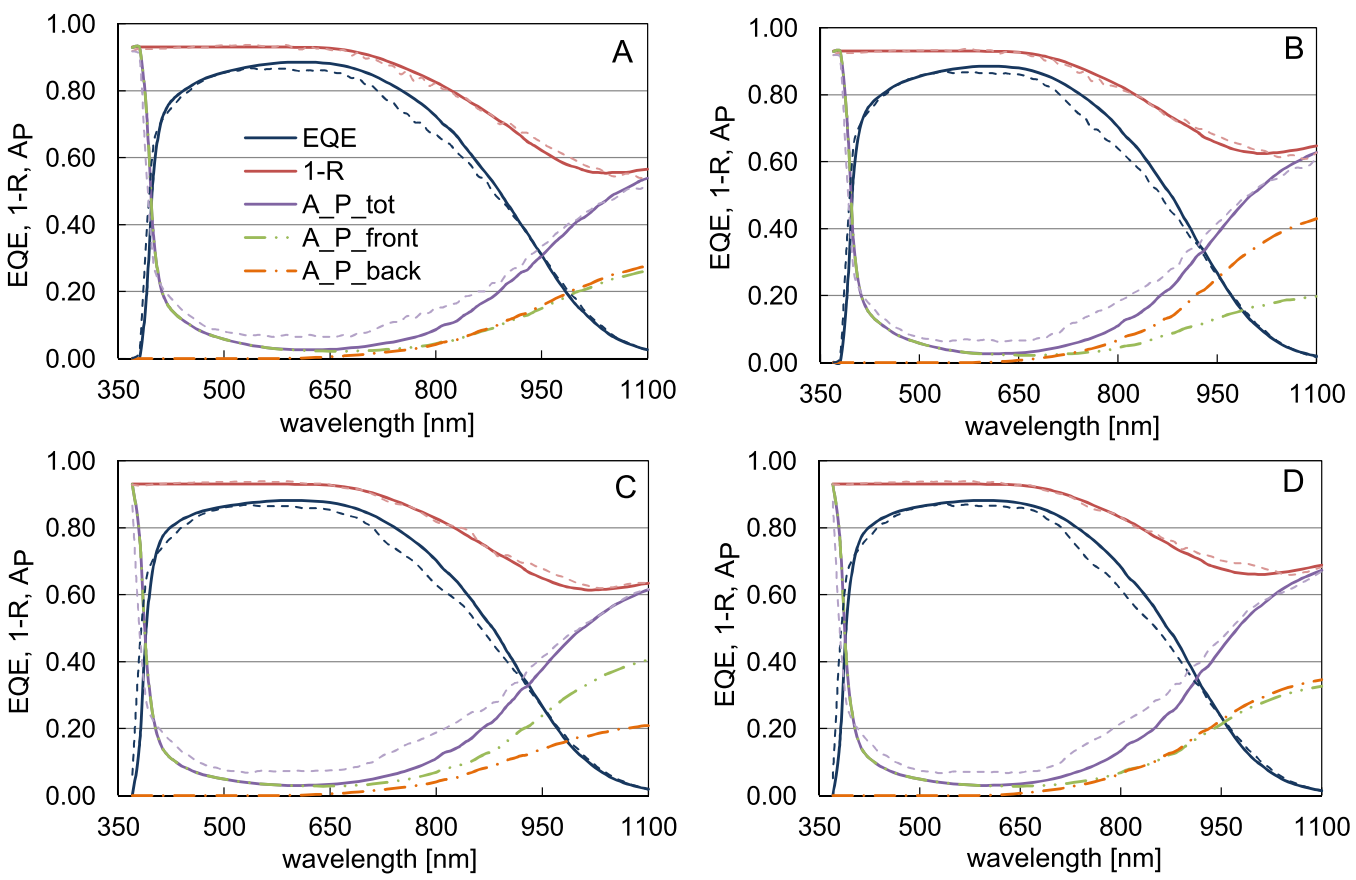

Fig. 5. Simulated (solid) and measured (dashed) EQE, total absorptance $(1-R)$ and front, back and total $A_{P}$ curves simulated from experimental absorption data for the micromorph devices presented in Figure 1.

The parasitic absorption curve experimentally deduced from $A_{P}=1-\mathrm{EQE}-R$ is also plotted, as well as the curves representing calculated parasitic absorption which is attributed to the front side of the device $\left(A_{P}^{\text {front }}\right)$, to the back side $\left(A_{P}{ }^{b a c k}\right)$, and the total parasitic absorption $\left(A_{P}{ }^{\text {tot }}\right)$. It should be noted that possible collection issues are assimilated to $A_{P}$ in the measurements, whereas a $98 \%$ collection efficiency was set for the whole spectrum in the model for all four cases - explaining the $2 \%$ higher $A_{P}$ in all cases for the experimental case compared to the modeled case. As suggested by experimental measurements, $A_{P}^{\text {front }}$ (resp. $A_{P}^{\text {back }}$ ) is also influenced by the transparency of the layers at the back (resp. front) of the device: $A_{P}{ }^{\text {front }}$ is different between cases $\mathrm{A}$ and B, even though all layers at the front of the cell are unchanged. Also, for wavelengths larger than $700 \mathrm{~nm}$, very similar $A_{P}{ }^{\text {front }}$ and $A_{P}{ }^{\text {back }}$ are observed in symmetrical devices (A and D), which is in agreement with experimental findings.

\section{Conclusion}

We showed in this work that parasitic absorption in both electrodes of a solar cell has similar effect in the infra-red part of the spectrum. We assessed this result with simulations which reproduce well the observed trends. We also emphasized that a reduction of parasitic absorption in one electrode yields a larger EQE gain when the other electrode is made more transparent. Reducing the doping of TCO layers and compensating by thickness increase is shown to be an efficient way of reducing parasitic absorption in these layers. By using very transparent TCO layers and high-quality silicon layers, a micromorph device with $11.75 \%$ stable efficiency, independently certified by Fraunhofer ISE was obtained.

We thank the Swiss Federal Office for Energy for funding under grant SI/500750-01. A part of this work was carried out in the framework of the FP7 project "Fast Track", funded by the EC under Grant agreement No. 283501.

\section{References}

1. O.D. Miller, E. Yablonovitch, S.R. Kurtz, IEEE J. Photovolt. 2, 303 (2012)

2. C. Battaglia, L. Erni, M. Boccard, L. Barraud, J. Escarre, K. Soederstroem, G. Bugnon, A. Billet, L. Ding, M. Despeisse, F.-J. Haug, S. De Wolf, C. Ballif, J. Appl. Phys. 109, 114501 (2011)

3. S. Calnan, A.N. Tiwari, Thin Solid Films 518, 1839 (2010)

4. T. Koida, H. Fujiwara, M. Kondo, Sol. Energy Mater. Sol. Cells 93, 851 (2009)

5. Y. Tsunomura, Y. Yoshimine, M. Taguchi, T. Baba, T. Kinoshita, H. Kanno, H. Sakata, E. Maruyama, M. Tanaka, Sol. Energy Mater. Sol. Cells 93, 670 (2009)

6. H.W. Deckman, C.R. Wronski, H. Witzke, E. Yablonovitch, Appl. Phys. Lett. 42, 110968 (1983)

7. M. Boccard, C. Battaglia, F.-J. Haug, M. Despeisse, C. Ballif, Appl. Phys. Lett. 101, 151105 (2012)

8. B. Stannowski, O. Gabriel, S. Calnan, T. Frijnts, A. Heidelberg, S. Neubert, S. Kirner, S. Ring, M. Zelt, B. Rau, J.-H. Zollondz, H. Bloess, R. Schlatmann, B. Rech, Sol. Energy Mater. Sol. Cells 119, 196 (2013)

9. H. Sai, T. Koida, T. Matsui, I. Yoshida, K. Saito, M. Kondo, Appl. Phys. Express 6, 104101 (2013)

10. A. Feltrin et al., Sol. Energy Mater. Sol. Cells 119, 219 (2013) 
11. H. Tan, R. Santbergen, A.H.M. Smets, M. Zeman, Nano Lett. 12, $4070(2012)$

12. B. Lipovšek, J. Krč, O. Isabella, M. Zeman, M. Topič, Phys. Stat. Sol. (c) 7, 1041 (2010)

13. J. Krc et al., J. Non-Cryst. Solids 352, 1892 (2006)

14. J. Müller, B. Rech, J. Springer, M. Vanecek, Sol. Energy 77, 917 (2004)

15. J.M. Gee, in Photovoltaic Specialists Conference, Conference Record of the Twentieth IEEE, Las Vegas, USA, 1988, pp. 549-554

16. M. Boccard, P. Cuony, C. Battaglia, M. Despeisse, C. Ballif, Phys. Stat. Sol. Rapid Res. Lett. 4, 326 (2010)

17. M. Berginski, J. Hüpkes, M. Schulte, G. Schöpe, H. Stiebig, B. Rech, M. Wuttig, J. Appl. Phys. 101, 074903 (2007)

18. Youn Ho Heo, Dong Joo You, Hyun Lee, Sungeun Lee, Heon-Min Lee, Sol. Energy Mater. Sol. Cells 122, 107 (2014)

19. L. Ding, M. Boccard, G. Bugnon, M. Benkhaira, S. Nicolay, M. Despeisse, F. Meillaud, C. Ballif, Sol. Energy Mater. Sol. Cells 98, 331 (2012)
20. P. Cuony, D.T.L. Alexander, I. Perez-Wurfl, M. Despeisse, G. Bugnon, M. Boccard, T. Soderstrom, A. Hessler-Wyser, C. Hebert, C. Ballif, Adv. Mater. 24, 1182 (2012)

21. A. Lambertz, T. Grundler, F. Finger, J. Appl. Phys. 109, 113109 (2011)

22. S. Faÿ, L. Feitknecht, R. Schlüchter, U. Kroll, E. VallatSauvain, A. Shah, Sol. Energy Mater. Sol. Cells 90, 2960 (2006)

23. P. Cuony, Ph.D. thesis, EPFL, 2012

24. J. Steinhauser, Ph.D. thesis, University of Neuchâtel, 2008

25. M. Boccard, T. Soderstrom, P. Cuony, C. Battaglia, S. Hanni, S. Nicolay, L. Ding, M. Benkhaira, G. Bugnon, A. Billet, M. Charriere, F. Meillaud, M. Despeisse, C. Ballif, IEEE J. Photovolt. 2, 229 (2012)

26. G. Bugnon, G. Parascandolo, S. Hänni, M. Stuckelberger, M. Charrière, M. Despeisse, F. Meillaud, C. Ballif, Sol. Energy Mater. Sol. Cells 120, 143 (2014)

27. S. Hänni, G. Bugnon, G. Parascandolo, M. Boccard, J. Escarré, M. Despeisse, F. Meillaud, C. Ballif, Prog. Photovolt.: Res. Appl. 21, 821 (2013) 